\title{
A Milk Diet Partly Containing Soy Protein Does Not Change Growth but Regulates Jejunal Proteins in Young Goats ${ }^{1}$
}

\author{
S. Kuhla, ${ }^{\star}$ P. E. Rudolph,† D. Albrecht,‡ U. Schoenhusen, ${ }^{\star}$ R. Zitnan,§ W. Tomek,\# K. Huber,\| \\ J. Voigt, ${ }^{\star}$ and C. C. Metges ${ }^{\star 2}$ \\ *Research Unit Nutritional Physiology "Oskar Kellner", and \\ †Research Unit Genetics and Biometry, Research Institute for the Biology of Farm Animals (FBN), D-18196 Dummerstorf, Germany \\ †Institute of Microbiology, Ernst-Moritz-Arndt-University, Greifswald, D-17489 Greifswald, Germany \\ §Institute of Animal Production, Slovak Institute for Agricultural Research Nitra, Division Kosice, SK-04001 Kosice, Slovak Republic \\ \#Research Unit Reproductive Biology, Research Institute for the Biology of Farm Animals (FBN), D-18196 Dummerstorf, Germany \\ ||Department of Physiology, School of Veterinary Medicine, Hannover, D-30173 Hannover, Germany
}

\section{ABSTRACT}

Soy protein is known to alter intestinal function and structure. We determined in young goats whether a diet partly containing soy protein differently affects intestinal morphology and the jejunal and hepatic proteome as compared with a milk diet. Fourteen male 2wk-old White German dairy goat kids were fed comparable diets based on whole cow's milk in which $35 \%$ of the crude protein was casein (milk protein group; MP) or soy protein supplemented by indispensable AA (SPAA) for $34 \mathrm{~d}$ ( $\mathrm{n}=7$ /group). Body weight gain and food efficiency were not different. Jejunal and hepatic tissue was collected to determine intestinal morphology by microscopy and protein repertoire by 2 -dimensional gel electrophoresis and mass spectrometry. Jejunal crypt depth was reduced and villus height to crypt depth ratio was higher in SPAA than in milk protein. Out of 131 proteins identified, 32 proteins were found to be differently expressed in both groups. In SPAA, downregulated jejunal proteins were involved in processes related to cytoskeleton generation, protein, lipid, and energy metabolism. Downregulated hepatic proteins were related to glycolysis and Krebs cycle. Thirteen proteins were upregulated in SPAA. Among these, 2 hepatic proteins were related to carbohydrate breakdown. The other 11 jejunal proteins were involved in cytoskeleton assembly, proteolysis, and carbohydrate breakdown. In addition, glutathione-S-transferase was found to be upregulated in the medial jejunum. In conclusion, a SPAA diet as compared with a milk diet was related to changes in jejunal morphology and jejunal

\footnotetext{
Received January 11, 2007.

Accepted May 18, 2007.

${ }^{1}$ Financial support was received from the core budget to the Research Institute for the Biology of Farm Animals and the Alexander von Humboldt foundation, Bonn, Germany (RZ).

${ }^{2}$ Corresponding author: metges@fbn-dummerstorf.de
}

proteins relevant for protein turnover, energy metabolism, and cytoskeleton assembly with no apparent impact on animal BW gain.

Key words: intestinal development, goat kid, proteome analysis, soy protein

\section{INTRODUCTION}

Alternate-protein milk replacer formulas for suckling preruminants containing $50 \%$ or less of total protein as soy protein (SP) have been shown to reduce growth and feed efficiency in young ruminants when compared with whole milk or casein diets (Lallès, 1993; Kanjanapruthipong, 1998; Drackley et al., 2006). This might be associated to changes of small intestinal mucosa with deterioration of villus integrity and decreased villus height and crypt cell depth (Seegraber and Morrill, 1986; Zitnan et al., 2005; Drackley et al., 2006) with consequences for absorptive function (Seegraber and Morrill, 1986; Kanjanapruthipong, 1998). In line with this are findings showing SP to support growth and gut and liver protein synthesis in rats and pigs to a lesser degree than casein meals (Deutz et al., 1998; Tachibana et al., 2005). A diet containing SP as the sole protein source alters hepatic gene and protein expression in young pigs (Schwerin et al., 2002; Junghans et al., 2004b). Besides isoflavones and antigenic factors such as beta-conglycinine present in SP (Payne et al., 2001; Ren et al., 2001), a known deficit of indispensable AA can be responsible for the above-mentioned effects, and supplementation of dietary SP with indispensable AA (Lys, Met, Thr) improved growth and nitrogen accretion in young calves (Pelaez and Walker, 1979; Kanjanapruthipong, 1998). We recently found an altered RNA metabolism in the small intestinal mucosa of young goats fed a diet partly containing SP supplemented with AA as compared with a whole milk/casein-based diet (Schoenhusen et al., 2007). We therefore were interested to explore whether this diet also changes protein expression patterns in 
Table 1. Ingredients and chemical composition of milk or soy protein containing diets fed to goat kids

\begin{tabular}{lrr}
\hline & \multicolumn{2}{c}{ Diet $^{1}$} \\
\cline { 2 - 3 } & MP & SPAA \\
\hline Ingredient, g/kg of DM feed & 752 & 727 \\
Cow milk & 100 & - \\
Casein $^{2}$ & - & 160 \\
Soy protein product & & 104 \\
Lactose & 148 & 9 \\
AA mixture & - & \\
Chemical composition & 170 & 169 \\
DM, g/kg & 41 & 49 \\
Crude ash, g/kg of DM & 307 & 307 \\
CP, g/kg of DM & 242 & 240 \\
Ether extract, g/kg of DM & 0 & 6 \\
Crude fiber, g/kg of DM & 410 & 398 \\
Nitrogen-free extract, g/kg of DM & 403 & 351 \\
Lactose, g/kg of DM & 17.8 & 17.5 \\
ME, MJ/kg of DM & & \\
\hline
\end{tabular}

${ }^{1} \mathrm{MP}=$ milk diet containing $\mathrm{CN}$ (35\% of the milk $\mathrm{CP}$ was replaced by casein). SPAA = milk diet containing soy protein product supplemented with AA (35\% of total $\mathrm{CP}$ in the diet).

${ }^{2}$ Acid-precipitated casein, Molkereigesellschaft Lauingen $\mathrm{GmbH}$, Lauingen, Germany.

${ }^{3}$ Soy product Hamlet 300, Hamlet Protein A/S, Horsens, DK. Composition of the soy protein product (g per $100 \mathrm{~g} \mathrm{DM}$ ): crude ash, 6.3, $\mathrm{CP}, 61.8$, ether extract, 1.8, crude fiber, 3.8. Isoflavone content (per $\mathrm{kg}$ of DM soy protein product): $907 \mathrm{mg}$ of daidzein, 1,959 $\mathrm{mg}$ of genistein.

${ }^{4}$ Composition (g per $100 \mathrm{~g}$ of AA mixture): Thr, 5; Val, 19; Ile, 7; Leu, 24; His, 6; Lys, 23; Met, 16.

jejunal and liver protein, bearing in mind that specific proteins must be involved in the processes leading to the above-described structural and functional alterations.

\section{MATERIALS AND METHODS}

\section{Animals, Feeding, and Experimental Procedures}

Goat kids were housed and treated in accordance with the guidelines for the use of animals as experimental subjects of the state government in Mecklenburg-West Pommerania. Fourteen male kids (White German dairy goat) were purchased from a commercial goat farm at $6 \mathrm{~d}$ of age. After birth the kids stayed with their mothers to suck colostrum and milk. Upon arrival at the research institute, mean BW was $4.5 \pm 0.2 \mathrm{~kg}$ and the kids were fed cow's milk by nipple bottle 3 times a day $(0700,1200$, and $1600 \mathrm{~h})$. Goat kids were then randomly assigned to 2 dietary treatment groups of 7 kids each. Groups were housed in boxes $(3 \mathrm{~m} \times 2.5 \mathrm{~m})$ at an ambient temperature of about $15^{\circ} \mathrm{C}$ with free access to fresh water. At $14 \mathrm{~d}$ of age feeding of experimental diets was started and continued for $34 \mathrm{~d}$. Both experimental diets ( $17 \%$ DM, $5.2 \%$ protein, $4.1 \%$ fat; Table 1) were based on whole cow's milk (13\% DM, $3.3 \%$ protein, $3.6 \%$ fat, $4.9 \%$ lactose). In the milk group (MP) $35 \%$ of the milk
Table 2. Crude protein $(\mathrm{g} / 100 \mathrm{~g}$ of $\mathrm{DM})$ and AA contents $(\mathrm{g} / 16 \mathrm{~g}$ of N) of milk or soy protein containing diets

\begin{tabular}{lrr}
\hline & \multicolumn{2}{c}{ Diet $^{1}$} \\
\cline { 2 - 3 } Item & \multicolumn{1}{c}{ MP } & SPAA \\
\hline CP & 30.69 & 30.73 \\
Asp & 6.84 & 7.78 \\
Thr & 4.02 & 3.96 \\
Ser & 5.00 & 4.64 \\
Glu & 21.28 & 19.03 \\
Gly & 1.78 & 2.43 \\
Ala & 3.06 & 3.46 \\
Val & 5.93 & 6.00 \\
Ile & 5.02 & 4.98 \\
Leu & 9.03 & 9.06 \\
Tyr & 3.91 & 3.28 \\
Phe & 4.78 & 4.76 \\
His & 2.67 & 2.56 \\
Lys & 7.87 & 7.74 \\
Arg & 3.26 & 4.10 \\
Pro & 9.74 & 7.73 \\
Cys & 0.65 & 0.96 \\
Met & 2.30 & 2.20 \\
Trp & 1.31 & 1.26 \\
\hline
\end{tabular}

${ }^{1} \mathrm{MP}=$ milk diet containing $\mathrm{CN}$ (35\% of the milk $\mathrm{CP}$ was replaced by casein). SPAA = milk diet containing soy protein product supplemented with AA (Thr, Val, Ile, Leu, His, Lys, Met; 35\% of total CP in the diet).

protein was replaced by pure acid-precipitated casein (Molkereigenossenschaft GmbH, Lauingen, Germany), whereas in the soy protein group the same amount of milk protein was replaced by SP (Soy protein product HP 300, Hamlet Protein A/S, Horsens, Denmark; 6.3\% crude ash, $61.8 \% \mathrm{CP}, 1.8 \%$ ether extract, $3.8 \%$ crude fiber in DM) supplemented by those AA known to be lower concentrated in soy protein than in casein $(\mathrm{Thr}$, Val, Ile, Leu, His, Lys, Met; SPAA; Tables 1 and 2). Diets were formulated to be isonitrogenous and isocaloric (Tables 1 and 2). Lactose was added to provide a constant protein to $\mathrm{N}$-free extract ratio in both diets.

Preparation of experimental diets and feeding level were as described by Schoenhusen et al. (2007). Two kids had to be removed from the MP group because of clinical pneumonia.

On $\mathrm{d} 34,5 \mathrm{~h}$ after the morning feeding, kids were killed by stunning using a captive bolt pistol and bled from the carotid arteries. Blood samples were taken in tubes containing di-K-EDTA $(1.6 \mathrm{mg} / \mathrm{mL}$ of blood $)$ and held on crushed ice. After centrifugation $(1,500 \times g, 15$ min at $4^{\circ} \mathrm{C}$ ) plasma aliquots were stored at $-20^{\circ} \mathrm{C}$ for later analysis. Liver and segments from the proximal and medial jejunum were removed within 5 min after slaughter. The segments were rinsed free of digesta with ice-cold saline $[0.9 \%$ (wt/vol) $\mathrm{NaCl}]$. Tissue sections of $1 \mathrm{~cm}^{2}$ from each jejunal segment were cut and fixed in $4 \%$ formaldehyde solution for evaluation of jejunal mucosa morphology. Mucosal tissue was harvested 
from the remaining segments by separating sections along the longitudinal axis and scraping with a glass slide. Liver samples and mucosal tissues were frozen in liquid nitrogen, ground to fine powder, partitioned, and stored at $-80^{\circ} \mathrm{C}$ until analysis.

\section{Feed and AA Analysis}

Analyses of dietary constituents and AA were performed as described by Schoenhusen et al. (2007). Metabolizable energy in the diets was calculated using digestible nutrients as described (Society of Nutrition Physiology, 2001; Jentsch et al., 2003).

The concentrations of free amino acids in blood plasma were measured after deproteinization with sulfosalicylic acid by ion exchange chromatography using lithium buffer and physiological amino acid standard solutions (No. A9906, Sigma, Taufkirchen, Germany) with an amino acid analyzer (Biochrom 20; Pharmacia LKB, Cambridge, UK).

\section{Intestinal Morphology}

Intestinal tissue sections fixed in $4 \%$ formaldehyde solution were rinsed in water, the sections were dehydrated in a graded series of ethanol, cleared in benzene, saturated with and embedded in paraffin. Sections of 5 - $\mu$ m thickness ( 10 slices per sample) were stained with hematoxylin and eosin and viewed under a light microscope (Axiolab, Carl Zeiss, Jena, Germany). The height, width, circumference, and cut surface of 30 villi and depth of 30 crypts were determined by the computeroperated Image $\mathrm{C}$ picture analysis system (Intronic $\mathrm{GmbH}$, Berlin, Germany) and the IMES analysis program using a color video camera (Sony 3 CCD, Sony Electronics Ltd., Tokyo, Japan) microscopy analysis.

For scanning electron microscopy, intestinal tissue samples $\left(0.5 \mathrm{~cm}^{2}\right)$ were fixed in a mixture of $2 \%$ (wt/vol) paraformaldehyde and $2.5 \%$ (wt/vol) glutaraldehyde in $0.1 M$ sodium cacodylate buffer ( $\mathrm{pH} 7.2$ ). After washing in sodium cacodylate buffer sections were post fixed in $1 \%$ (wt/vol) osmic oxide and dehydrated through a graded series of ethanol, put in acetone, and finally dried in a critical point dryer with $\mathrm{CO}_{2}$ as transition fluid. Samples were then coated at $4^{\circ} \mathrm{C}$ with gold of 20$\mathrm{nm}$ thickness and examined using electron microscopy (Joel JEM-100 CX II; Joel Ltd., Akishima, Japan) with an ASID-4D high resolution scanning system at an accelerating voltage of $15 \mathrm{kV}$ (Zitnan et al., 1998).

\section{Two-Dimensional Gel Electrophoresis}

Two-dimensional gel electrophoresis (2-DE) was performed as described previously (Görg et al., 2000). In the first dimension proteins were separated by isoelectric focusing (IEF) and in the second dimension according to molecular mass by SDS-PAGE. An amount of $100 \mathrm{mg}$ powdered mucosa tissue was dissolved in $200-\mu \mathrm{L}$ lysis buffer ( $8 M$ urea, $2 \%$ (wt/vol) 3-[(3-cholamidopropyl)dimethyl-amonio]-1-propanesulfonate (CHAPS), $0.5 \%$ (vol/vol) immobilized $\mathrm{pH}$ gradient (IPG)-buffer, $40 \mathrm{~m} M$ dithiothreitol (DTT; all from Amersham Biosciences, Uppsala, Sweden), $5 \mathrm{mM}$ Pefabloc (Merck, Darmstadt, Germany) for 5 min using a commercial grinding kit (Amersham Biosciences). The lysate was centrifuged for $10 \mathrm{~min}$ at $11,000 \times g$ at $20^{\circ} \mathrm{C}$, and the supernatant containing the solubilized proteins was used directly. An aliquot was subjected to protein determination according to Bradford (1976) with a Bioquant-Protein reagent solution (Merck) using BSA as standard.

For separation in the first dimension sample solution $(20 \mu \mathrm{L})$ was added to $320 \mu \mathrm{L}$ of rehydration buffer $(8$ $M, 2 \%$ (wt/vol) CHAPS, $0.8 \%$ (vol/vol) IPG-buffer, 18 $\mathrm{m} M$ DTT, and a trace of bromophenol blue), mixed and loaded to $18-\mathrm{cm}$ long ready-made Immobiline DryStrip gels (IPG strip) containing a wide-range $\mathrm{pH}$ gradient 3 to 10. Rehydration was performed using an Amersham Ettan IPGphor IEF unit for $12 \mathrm{~h}$ at $50 \mathrm{~V}$, and IEF was carried out under the following conditions: $50 \mu \mathrm{A} / \mathrm{IPG}$ strip, $500 \mathrm{~V}$ for $1 \mathrm{~h}, 1,000 \mathrm{~V}$ for $1 \mathrm{~h}$, and $8,000 \mathrm{~V}$ for 4 h $20 \mathrm{~min}$. The amount of protein $(0.5$ to $0.6 \mathrm{mg}$ ) loaded onto an 18-cm IPG strip did not differ between the MP and SPAA groups. After IEF, strips were first equilibrated in buffer containing $0.05 M$ Tris $\mathrm{pH} 8.8,30 \%$ (vol/vol) glycerol, $6 M$ urea, 2\% (wt/vol) SDS, 1\% (wt/ vol) DTT followed by a second incubation in the same buffer except DTT was substituted by iodoacetamide $2.5 \%$ (wt/vol), each for $15 \mathrm{~min}$ under gentle agitation. Thereafter, strips were transferred on the surface of the laboratory-made SDS-PAGE $12.5 \%$ gels and embedded in low-melting agarose. The SDS-PAGE was performed according to Laemmli (1970) and run using an Amersham Biosciences Ettan DALTsix system (1.5 W/ gel for $1 \mathrm{~h}$, then $100 \mathrm{~W}$ ).

\section{Staining and Analysis of 2-Dimensional Gels}

The gels $(20 \times 20 \times 0.1 \mathrm{~cm})$ were fixed and stained overnight in 2.5\% (wt/vol) Coomassie Brilliant Blue R 250 solution comprising of $45 \%$ methanol and $10 \%$ acetic acid and destained in $15 \%$ methanol and $5 \%$ acetic acid and subsequently in aqua bidest until the background was clear. The gels were then scanned (200 dpi, 8 bit grayscale; Epson Perfektion 1250 scanner; Nagano, Japan).

The evaluation of the 2-DE gels was performed with 2-DE gel analysis software Delta2D (Decodon, Greifs- 
wald, Germany). The protein spot abundance in each gel was quantified in terms of percent volume, where the sum of all detected protein spots per gel represents $100 \%$. Independent protein samples of each tissue (liver, proximal, and medial epithelial tissue) from 5 animals each of group MP and group SPAA, respectively, were compared. Protein spots that differed at $P$ $<0.05$ in their abundance between diets, and selected remarkable spots were chosen for identification by matrix-assisted laser desorption/ionization time-of-flight mass spectrometry (MALDI-TOF MS) analysis.

Differences in protein expression among groups were indicated as fold change, which expresses the volume $(\%)$ of a given protein measured in the SPAA animals as a fraction of the same protein in the MP group. For example, if a given protein has a volume of 0.4 in the SPAA group, and a volume of 1.0 in the MP group, the fold change would be 0.4 , which means the expression volume of the given protein in SPAA is only $40 \%$ of that in MP. Further, after warping in pairs, image fusion was used to create a synthetic proteome map for each tissue analyzed containing all the spots from all gel images irrespective of the diet (Luhn et al., 2003).

\section{Identification of Proteins by Peptide Mass Fingerprinting}

The protein spots were excised from stained 2-dimensional gels (Ettan spot cutter, picker head of $2 \mathrm{~mm}$ diameter; Amersham Biosciences). Excised spots were transferred to 96-well microtiter plates. The tryptic digest with subsequent spotting on a MALDI-target was carried out automatically with the Ettan Spot Handling Workstation (Amersham Biosciences).

The molecular masses of tryptic digest were measured by MALDI-TOF MS (4800 MALDI TOF/TOF Analyzer; Applied Biosystems, Foster City, CA). The spectra were recorded in a mass range from 900 to 3,700 Da with a focus mass of 2,000 Da. For one main spectrum 30 subspectra with 60 shots per subspectrum were accumulated using a random search pattern. If the autolytical fragments of trypsin with the monoisotopic $(\mathrm{M}+\mathrm{H})^{+} \mathrm{m} / \mathrm{z}$ at 1,045.556 and 2,211.104 reached a signal to noise ratio $(\mathrm{S} / \mathrm{N})$ of at least 20 , an internal calibration was automatically performed as 2-point-calibration using these peaks. Peak lists were created using the "peak to mascot" script of the 4000 Series Explorer Software with the following settings: mass range from 900 to $3,800 \mathrm{Da}$, peak density of 15 peaks per $200 \mathrm{Da}$, minimal area of 100 , and maximal 60 peaks per spot, $\mathrm{S} / \mathrm{N}$ ratio of 10 .

To verify the results obtained by MALDI-TOF MS, MALDI-TOF-TOF analysis (4800 MALDI TOF/TOF Analyzer; Applied Biosystems) was performed. The 2 strongest peaks of the TOF-spectra were measured. For one main spectrum 25 subspectra with 125 shots per subspectrum were accumulated using a random search pattern. The internal calibration was automatically performed as 1-point-calibration with the monoisotopic arginine $(\mathrm{M}+\mathrm{H})^{+} \mathrm{m} / \mathrm{z}$ at 175.119 or lysine $(\mathrm{M}+\mathrm{H})^{+} \mathrm{m} / \mathrm{z}$ at 147.107 reached a signal to noise ratio of at least 5 . The peak lists were created as described above but with the following settings: mass range from 60 to precursor $-20 \mathrm{Da}$, peak density of 15 peaks per $200 \mathrm{Da}$, minimal area of 100 , and maximal 65 peaks per precursor, S/N ratio of 7 .

For the identification of proteins, database search with peptide mass fingerprinting of the analyte was performed against the databases NCBInr (National Center for Biotechnology Information, http://www. ncbi.nlm.nih.gov/; accessed June 1, 2006) and SwissProt (http://us.expasy.org/sprot/; accessed June 1, 2006) using the Mascot search engine version 2.1 (Matrix Science Ltd, London, UK).

\section{Statistics}

Data were expressed as means \pm SEM. To determine whether a protein was equally or differentially expressed, the volume (\%) of this protein was compared between the 2 feeding groups using Student's $t$-test. Differences in small intestinal morphology among feeding groups were analyzed by Student's $t$-test. Mean differences were considered as significant if $P<0.05$ and as a tendency if $0.05 \leq P<0.1$.

\section{RESULTS}

\section{Feed Intake, BW, and Plasma AA Concentration}

The animals were clinically healthy and daily DM (160 $\pm 5 \mathrm{~g}), \mathrm{CP}(49 \pm 2 \mathrm{~g})$, and metabolizable energy $(2.8 \pm 0.1 \mathrm{MJ})$ intakes were not different between both dietary groups. Growth performance did not differ (BW gain $136 \pm 4 \mathrm{~g} / \mathrm{d}$ and feed efficiency $1.18 \pm 0.02 \mathrm{~g}$ of $\mathrm{DMI} / \mathrm{g}$ of BW gain). Concentrations of plasma Thr, Ser, Gly, and Pro were lower in the SPAA group, but Phe was higher compared with MP (Table 3).

\section{Morphology of the Small Intestinal Mucosa}

The crypt depths in the proximal jejunum tended to be lower $(P<0.1)$, whereas the villus height to crypt depth ratios were higher $(P<0.05)$ in SPAA compared with MP (Table 4). In the medial jejunum the villus heights in the SPAA group tended to be decreased ( $P$ $<0.1$ ). Electron microscopy indicated that goat kids fed the MP diet had intestinal villi that were finger-shaped, long, round, and uniform. In contrast, kids fed SPAA 
Table 3. Blood plasma concentrations of AA $(\mathrm{nmol} / \mathrm{mL})$ of goat kids fed milk or soy protein containing $\operatorname{diets}^{1}$

\begin{tabular}{lcr}
\hline & \multicolumn{2}{c}{ Diet $^{2}$} \\
\cline { 2 - 3 } AA & \multicolumn{1}{c}{ MP } & SPAA \\
\hline Asp & $19 \pm 6$ & $14 \pm 1$ \\
Thr & $78 \pm 4$ & $64 \pm 2^{* *}$ \\
Ser & $140 \pm 13$ & $98 \pm 6^{* *}$ \\
Glu & $117 \pm 7$ & $135 \pm 6$ \\
Gln & $193 \pm 15$ & $200 \pm 10$ \\
Gly & $683 \pm 31$ & $538 \pm 36^{*}$ \\
Ala & $227 \pm 18$ & $186 \pm 13$ \\
Val & $300 \pm 3$ & $301 \pm 5$ \\
Met & $39 \pm 2$ & $40 \pm 2$ \\
Ile & $91 \pm 4$ & $91 \pm 5$ \\
Leu & $167 \pm 4$ & $166 \pm 7$ \\
Tyr & $68 \pm 3$ & $82 \pm 12$ \\
Phe & $55 \pm 3$ & $67 \pm 4^{*}$ \\
Orn & $60 \pm 10$ & $71 \pm 6$ \\
Lys & $98 \pm 4$ & $119 \pm 14$ \\
His & $45 \pm 3$ & $48 \pm 3$ \\
Arg & $88 \pm 8$ & $137 \pm 21$ \\
Hydroxy-Pro & $38 \pm 5$ & $31 \pm 2$ \\
Pro & $179 \pm 12$ & $136 \pm 10^{*}$ \\
\hline
\end{tabular}

${ }^{1}$ Values are means $\pm \operatorname{SEM}$; MP $(\mathrm{n}=5)$; $\operatorname{SPAA}(\mathrm{n}=7)$.

${ }^{2} \mathrm{MP}=$ milk diet containing $\mathrm{CN}$ ( $35 \%$ of the milk CP was replaced by casein) . SPAA = milk diet containing soy protein product supplemented with AA (Thr, Val, Ile, Leu, His, Lys, Met; 35\% of total CP in the diet).

Group differences: $* P<0.05 ; * * P<0.01$.

had villi that were less uniform, and showed a tendency to bend (Figure 1).

\section{Identification of Jejunal and Hepatic Proteins}

In proximal and medial jejunum total numbers of 868 and 1,144 distinct protein spots, respectively, were

Table 4. Effects of milk or soy protein containing diets on morphometry of the jejunum in goat kids ${ }^{1}$

\begin{tabular}{lccc}
\hline & & \multicolumn{2}{c}{ Diet $^{3}$} \\
\cline { 3 - 4 } Item & Site $^{2}$ & MP & SPAA \\
\hline Villus circumference, $\mu \mathrm{m}$ & Prox & $1,424 \pm 44$ & $1,362 \pm 36$ \\
& Med & $1,402 \pm 62$ & $1,328 \pm 30$ \\
Villus surface, $\mu \mathrm{m}^{2}$ & Prox & $79,498 \pm 2,879$ & $76,190 \pm 2,629$ \\
& Med & $80,379 \pm 4,520$ & $77,143 \pm 2,283$ \\
Villus height, $\mu \mathrm{m}$ & Prox & $583 \pm 15$ & $561 \pm 16$ \\
& Med & $624 \pm 18$ & $592 \pm 7 \dagger$ \\
Villus width, $\mu \mathrm{m}$ & Prox & $237 \pm 6$ & $231 \pm 6$ \\
& Med & $192 \pm 8$ & $195 \pm 6$ \\
Crypt depth, $\mu \mathrm{m}$ & Prox & $245 \pm 5$ & $226 \pm 8 \dagger$ \\
& Med & $223 \pm 5$ & $209 \pm 5 \dagger$ \\
Villus height:crypt depth & Prox & $2.38 \pm 0.04$ & $2.48 \pm 0.03^{*}$ \\
& Med & $2.81 \pm 0.08$ & $2.85 \pm 0.10$ \\
\hline
\end{tabular}

${ }^{1}$ Values are means \pm SEM; MP $(n=5)$; SPAA $(n=7)$.

${ }^{2}$ Prox $=$ proximal, med $=$ medial .

${ }^{3} \mathrm{MP}=$ milk diet containing $\mathrm{CN}$ (35\% of the milk $\mathrm{CP}$ was replaced by casein). SPAA = milk diet containing soy protein product supplemented with AA (35\% of total CP in the diet).

Group differences: $\dagger P<0.1 ; * P<0.05$. detected (Figures 2 and 3). Protein separation in liver samples yielded 1,123 protein spots (Figure 4 ). We selected 93,86 , and 68 spots from proximal and medial jejunum, and liver, respectively, to be analyzed by MALDI-TOF MS, of which 57, 48, and 26 spots could be identified based on homology with protein sequences mainly from humans, bovine, and pig species. All protein spots contained a single protein. Comigrating proteins were not detected, whereas 11 proteins were observed in more than one spot. For example, in proximal jejunum serum albumin precursor was represented by 7 of 57 spots (Table 5).

Within a total of 131 protein spots identified, 99 were equally expressed in the investigated tissues. Twentyfour percent of these proteins belonged to protein folding and protection, $20 \%$ to cytoskeletal proteins, $14 \%$ to energy, signal transduction and RNA processing, $17 \%$ to transport proteins, $8 \%$ to protein metabolism, $4 \%$ to lipid metabolism, and $13 \%$ to carbohydrate metabolism. Thirty-two proteins were found to be differently expressed between MP and SPAA $(P<0.05)$, with 15 proteins differently expressed in proximal jejunum, whereas the abundance of 10 and 7 proteins differed in medial jejunum and liver, respectively (Table 5). Of these 32 proteins 19 were decreased in the SPAA group $(\Delta$-fold change $<1.0)$ of which the jejunal proteins belonged to processes related to cytoskeleton assembly, protein synthesis, energy, and lipid metabolism. Hepatic proteins lower expressed in the SPAA group were related to serum albumin, glycolysis, and TCA cycle. Thirteen proteins were identified to be higher expressed in the SPAA than in the MP group ( $\Delta$-fold change $>1.0$; Table 5). Among these, 2 occurred in the liver and were related to carbohydrate breakdown. The other 11 proteins in the jejunum were involved in cytoskeleton assembly, proteolysis, and carbohydrate breakdown. In addition, glutathione-S-transferase was found to be upregulated in the medial jejunum.

In the proximal jejunum the largest proportion of proteins among all 15 identified to be differently expressed were involved in cytoskeleton assembly (28\%), protein folding and protection (16\%), and energy, signal transduction, and RNA processing (16\%; Figure 5). A quarter of all proteins identified in the medial jejunum belonged to processes of protein folding and protection followed by transport proteins. The largest proportion of hepatic proteins identified was related to carbohydrate metabolism.

\section{DISCUSSION}

Although the immense potential of proteome analysis for nutrition research has been well recognized (Daniel, 2002; Wang et al., 2006), relatively few studies have 
A

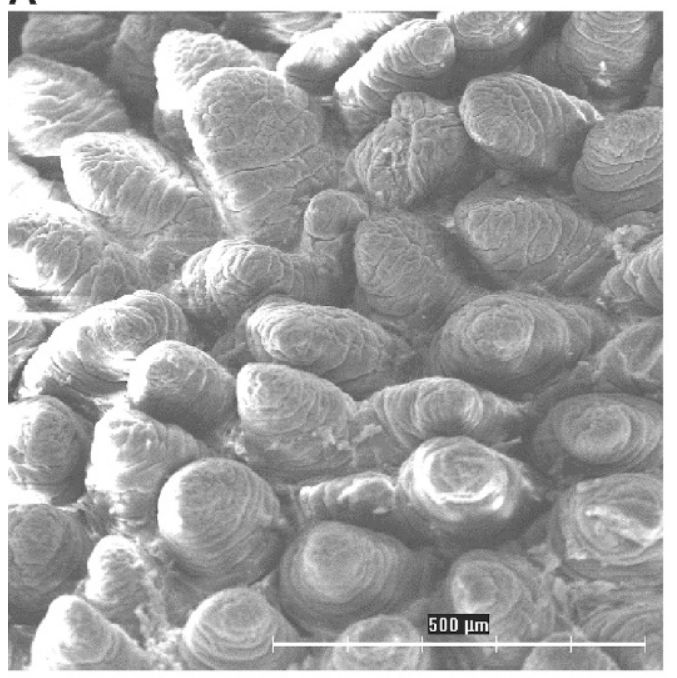

C

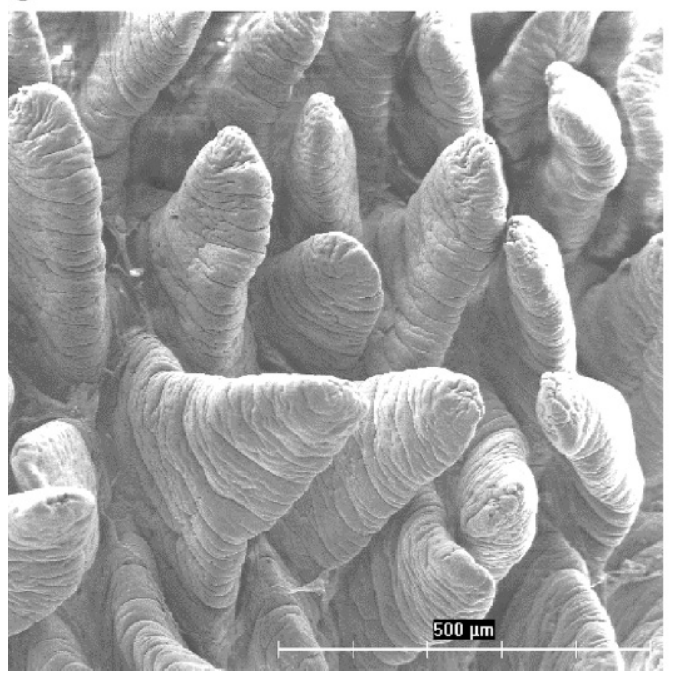

B



D

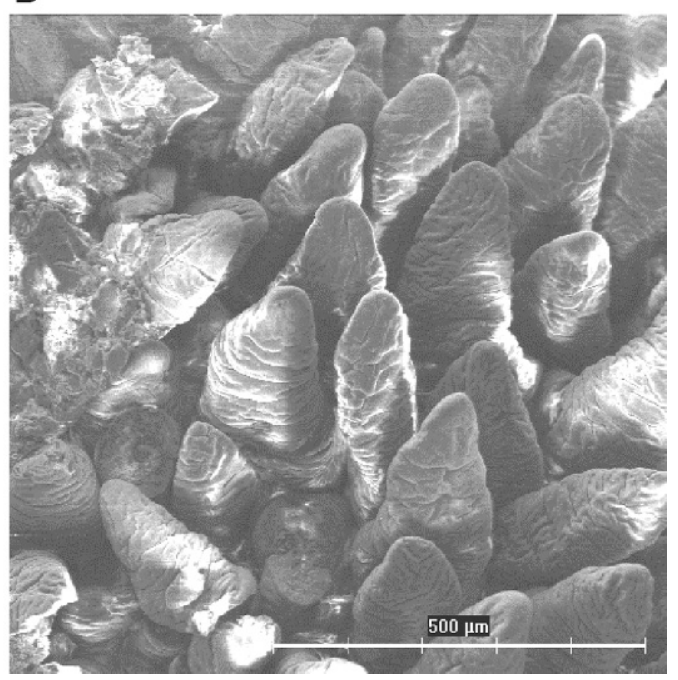

Figure 1. Representative scanning electron micrographs of villi in jejunum of goat kids fed a milk-based diet containing casein (MP, proximal: A, medial: C), and a milk replacer containing a soy protein product with AA supplementation (SPAA, proximal: B, medial: D); $\times$ $240 . \mathrm{MP}=$ milk diet containing $\mathrm{CN}$ ( $35 \%$ of the milk $\mathrm{CP}$ was replaced by casein). SPAA = milk diet containing soy protein product supplemented with $\mathrm{AA}(35 \%$ of total $\mathrm{CP}$ in the diet).

reported actual diet-related changes in tissue protein patterns in animals, and mostly due to single nutrient deficiencies in rats and chickens (Gianazza et al., 2003; Chanson et al., 2005; Corzo et al., 2005, 2006; tom Dieck et al., 2005; Tosco et al., 2005). Thus, to our knowledge this is the first report on the splanchnic proteome map in young goats as affected by dietary protein source.

Diets containing SP at 50\% or less of total protein can reduce growth or splanchnic protein synthesis when compared with milk protein containing diets (Deutz et al., 1998; Kanjanapruthipong, 1998; Drackley et al., 2006), which is in part related to lower amounts of Lys, Thr, Met, and branched-chain AA in SP (NRC, 1998; Junghans et al., 2004a). We aimed to overcome the known growth depression related to AA limitation by supplementing the most limiting indispensable AA in SP than compared with a milk protein diet. As a result we found the SPAA fed animals growing at a similar rate as MP animals. In line with this observation, we found the majority of proteins identified (i.e., 99 proteins) equally expressed. Eleven proteins were found in more than one spot. This was also reported by others for a range of tissues and is related to precursors, fragments, splicing variants, or posttranslationally modified forms of the concerned protein (Ellederova et al., 2004; D'Ambrosio et al., 2005).

In spite of AA supplementation we still found different concentrations in 5 of 20 plasma AA (Table 3). Lower 


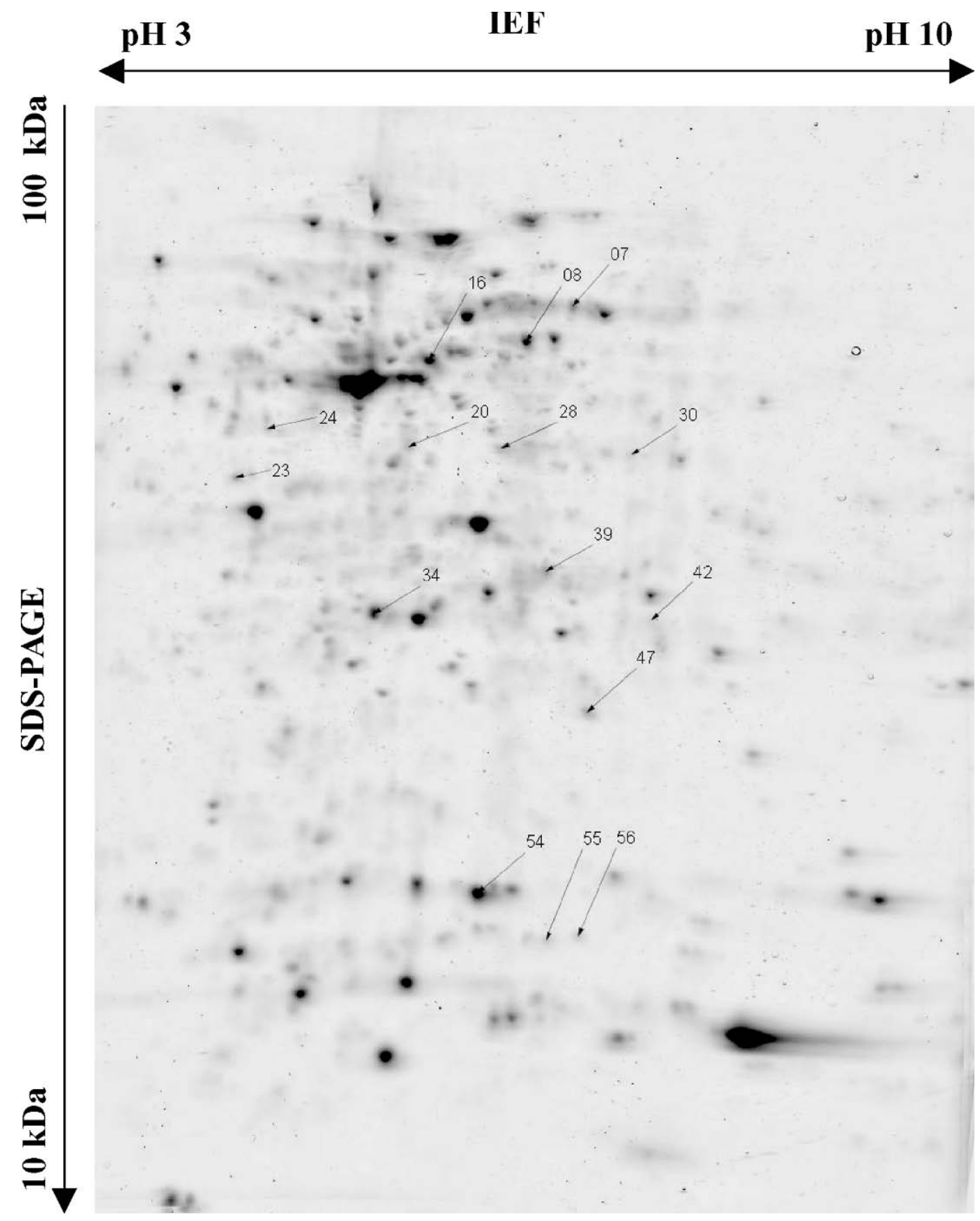

Figure 2. Total 2-dimensional proteome map of proximal jejunal mucosa in goat kids. Proteins were separated by isoelectric focusing (IEF) in 18-cm-long immobilized $\mathrm{pH}$ gradient (IPG) strips containing linear $\mathrm{pH}$ range 3 (left) to 10 (right), respectively, followed by SDSPAGE in vertical $12.5 \%$ gels. Molecular masses $\sim 10 \mathrm{kDa}$ and $\sim 100 \mathrm{kDa}$. The gels were stained with Coomassie blue, and numbered spots were analyzed by matrix-assisted laser desorption/ionization time-of-flight mass spectrometry. Corresponding differentially expressed proteins are reported in Table 5.

plasma concentrations of Ser and Pro are probably related to lower Ser and Pro content in the SPAA diet. In spite of a higher Gly concentration in SPAA, the lower plasma concentration observed suggests that Gly was probably used for the de novo purine nucleotide biosynthesis in intestinal mucosa (Schoenhusen et al., 2007). In addition, Ser is the precursor for Gly synthesis, which also might partly explain low Gly levels in the SPAA group. The Thr intake with the 2 diets was equivalent, but plasma Thr level was lower with SPAA, 


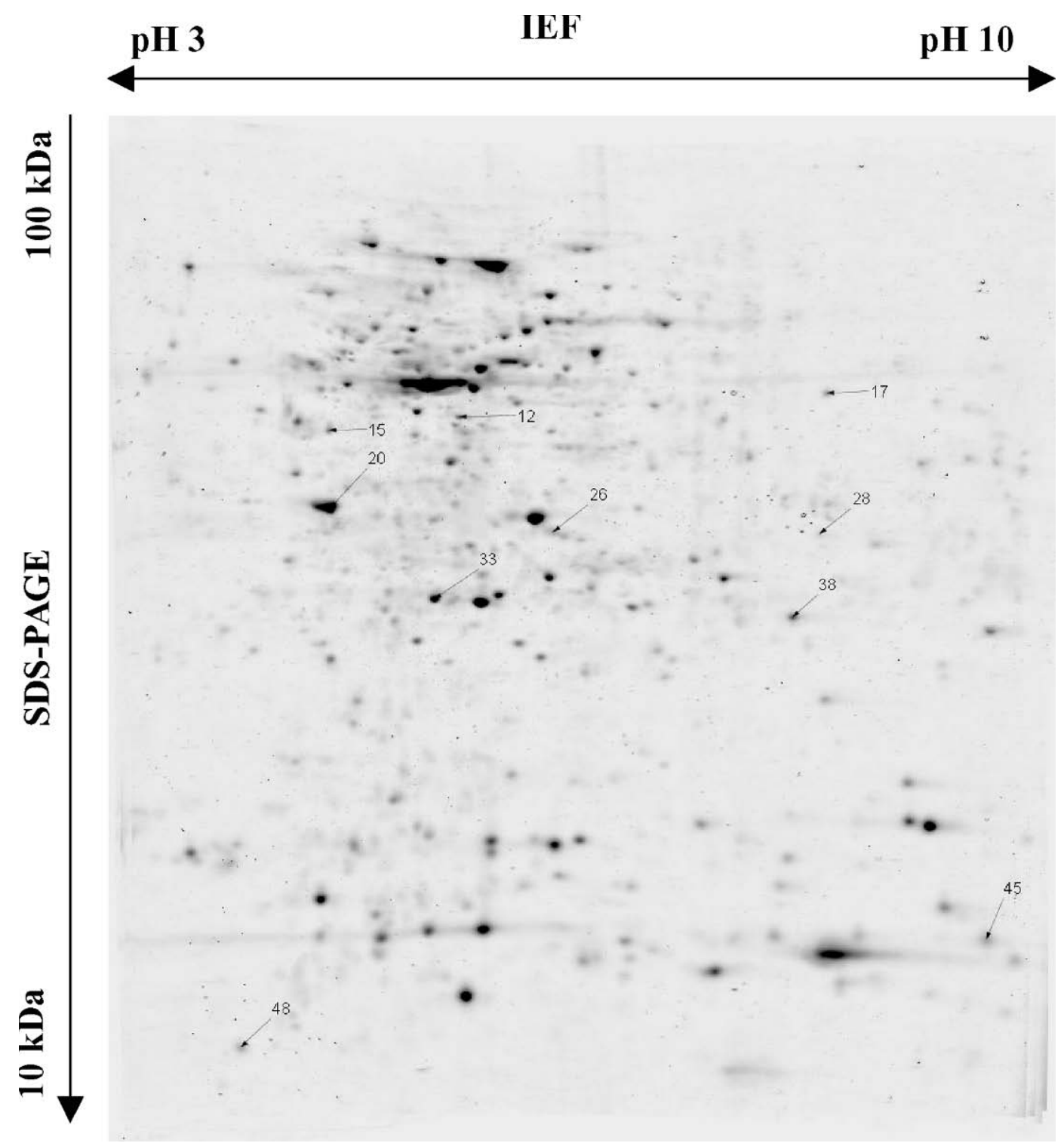

Figure 3. Total 2-dimensional proteome map of medial jejunal mucosa in goat kids. Proteins were separated by isoelectric focusing (IEF) in 18-cm-long immobilized $\mathrm{pH}$ gradient (IPG) strips containing linear $\mathrm{pH}$ range 3 (left) to 10 (right), respectively, followed by SDS-PAGE in vertical $12.5 \%$ gels. Molecular masses $\sim 10 \mathrm{kDa}$ and $\sim 100 \mathrm{kDa}$. The gels were stained with Coomassie blue, and numbered spots were analyzed by matrix-assisted laser desorption/ionization time-of-flight mass spectrometry. Corresponding differentially expressed proteins are reported in Table 5.

which could be related to a lower ileal digestibility of Thr with SP (Kanjanapruthipong, 1998) or the fact that some of the Thr in the SPAA group was in free form. Free dietary AA are more prone to oxidation compared with protein-bound AA (Metges et al., 2000).

There were still small differences regarding intestinal morphology. The increase of the villus height:crypt depth ratio in proximal jejunum of the SPAA-fed goats might indicate enhanced absorptive capacity (Table 4). In terms of specific proteins possibly related to the jejunal morphology we found a downregulation of proteins related to the cytoskeleton and muscle contraction in goat kids fed the SPAA diet. A reduced expression of hepatic genes related to cytoarchitecture was also shown in SP-fed rats (Tachibana et al., 2005). Proteins belonging to the major cellular proteolytic system, the proteasome (Coux et al., 1996), were upregulated, whereas 40 S ribosomal protein S12 involved in the protein synthesis machinery and proteins related to energy and signal transduction were concurrently downregulated. This is in agreement with a lower protein content found in the small intestinal mucosa of preruminant 


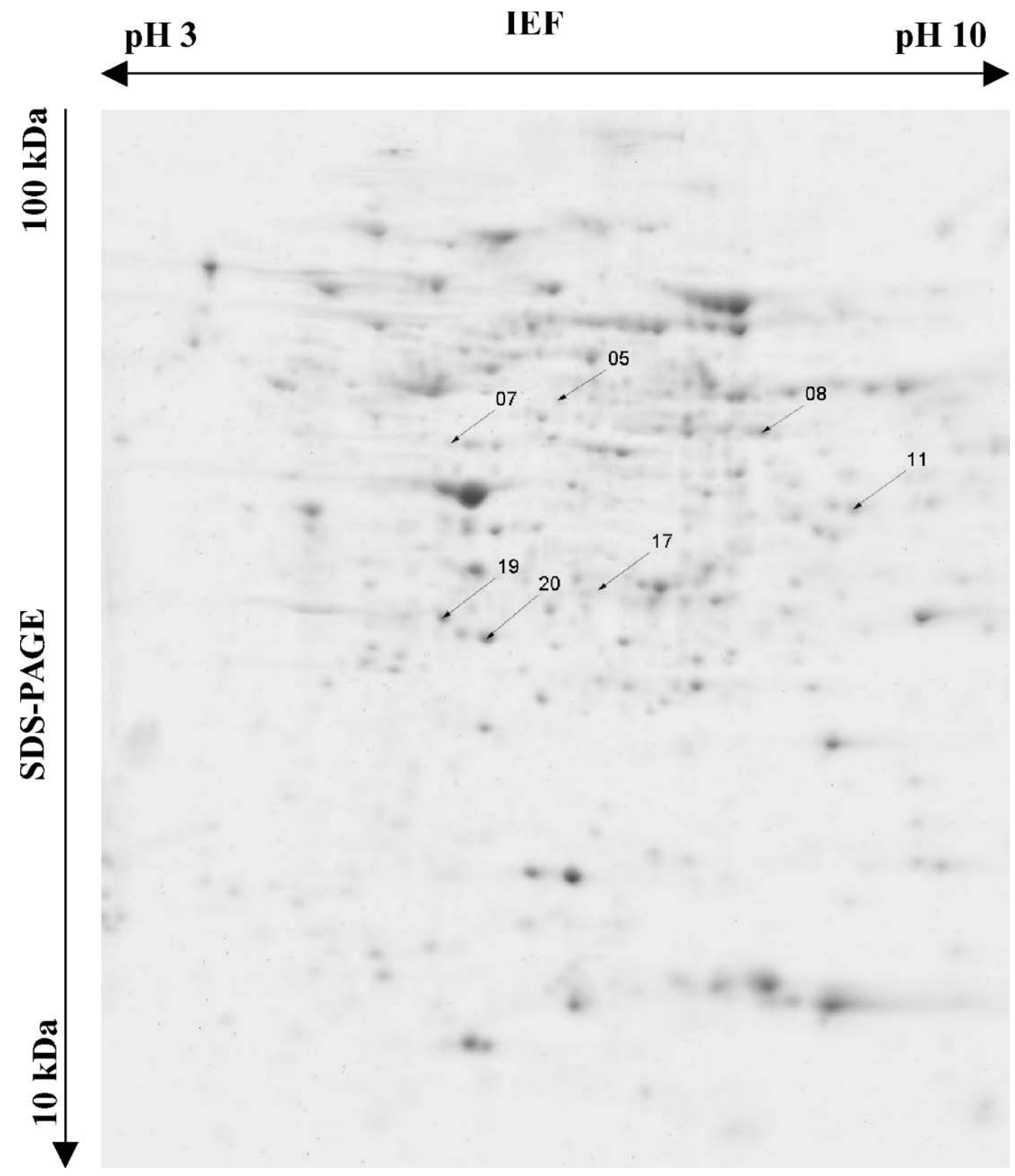

Figure 4. Total 2-dimensional proteome map of goat kids liver. Proteins were separated by isoelectric focusing (IEF) in 18-cm-long immobilized $\mathrm{pH}$ gradient (IPG) strips containing linear $\mathrm{pH}$ range 3 (left) to 10 (right), respectively, followed by SDS-PAGE in vertical $12.5 \%$ gels. Molecular masses $\sim 10 \mathrm{kDa}$ and $\sim 100 \mathrm{kDa}$. The gels were stained with Coomassie blue, and numbered spots were analyzed by matrixassisted laser desorption/ionization time-of-flight mass spectrometry. Corresponding differentially expressed proteins are reported in Table 5.

goat kids fed SPAA (Schoenhusen et al., 2007) and may be related to a local difference in intestinal AA availability with effects on protein turnover as indicated by reduced plasma AA concentrations in the SPAA group (Table 3).

Another possible explanation for differences in splanchnic protein expression is the presence of isoflavones in SP-containing diets. Isoflavones have been shown to affect the protein expression profile in cell culture (Fuchs et al., 2005, 2006). The SPAA diet used here contained genistein at a level of $312 \mathrm{mg} / \mathrm{kg}$ of DM feed. It has been reported that genistein at a dose of about $100 \mathrm{mg} / \mathrm{kg}$ of DM soy formula inhibits jejunal enterocyte proliferation and migration in piglets (Chen et al., 2005). This would agree with our finding of decreased jejunal villus heights and crypt depths. Thus, we conclude that differences in jejunal morphology and protein composition could be due to local suboptimal 
Table 5. Differentially expressed jejunal and liver proteins of goat kids fed milk or soy protein containing diets ${ }^{1}$

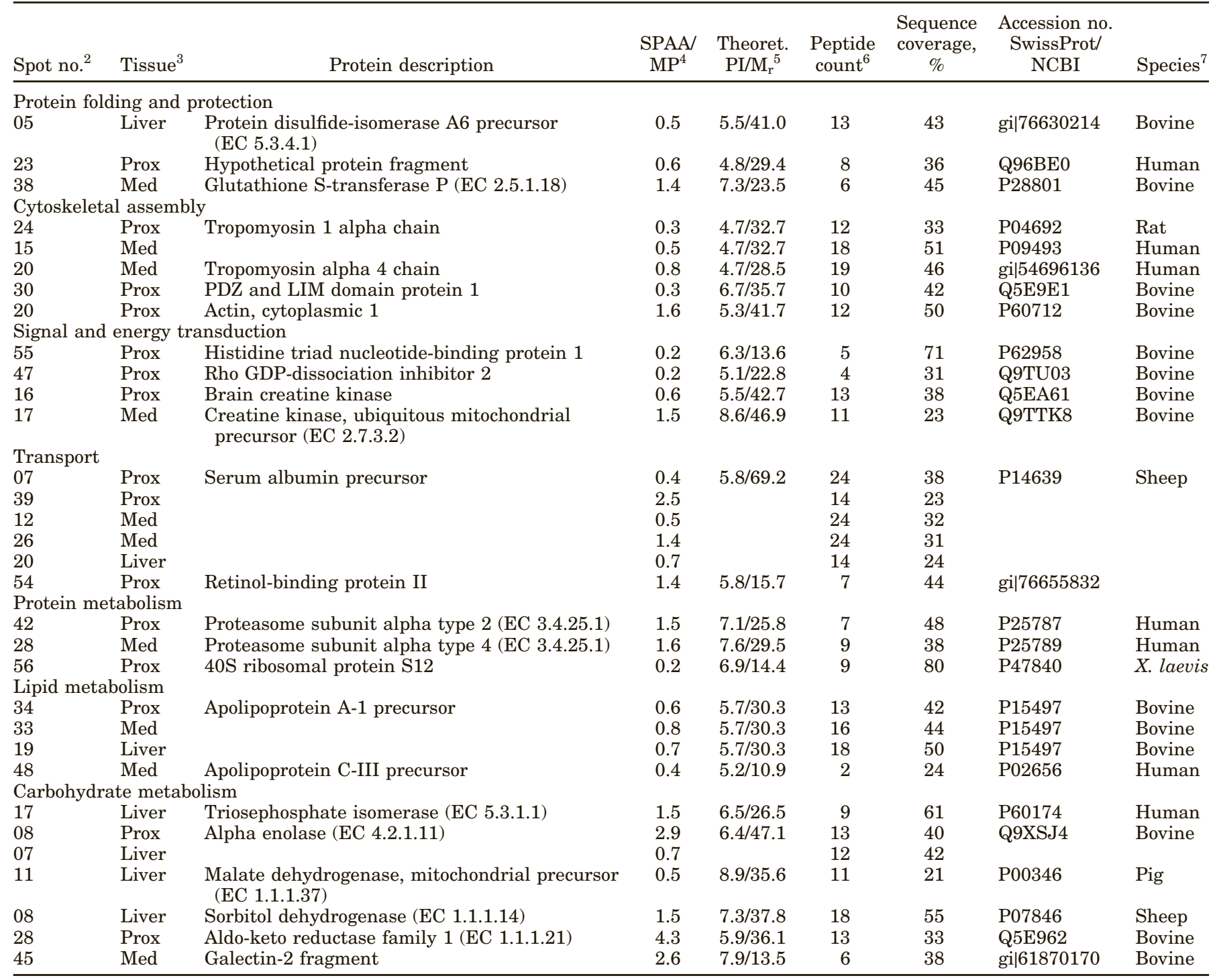

${ }^{1} \mathrm{MP}=$ milk diet containing $\mathrm{CN}$ (35\% of the milk $\mathrm{CP}$ was replaced by casein); SPAA = milk diet containing soy protein product supplemented with AA (35\% of total CP in the diet); $\mathrm{n}=5$ animals per group; $P<0.05$.

${ }^{2}$ Spots are shown in Figures 2, 3, 4 .

${ }^{3}$ Prox $=$ proximal jejunum, Med = medial jejunum.

${ }^{4} \Delta$-fold change, $\%$ spot volume SPAA/\% spot volume MP.

${ }^{5} \mathrm{PI}=$ isoelectric point; $\mathrm{M}_{\mathrm{r}}=$ average isotopic mass $(\mathrm{kDa})$.

${ }^{6}$ Number of peptides matched.

${ }^{7}$ X. laevis $=$ Xenopus laevis, African clawed frog.

AA patterns and a subsequent imbalance of protein synthesis and breakdown, the effects of isoflavones, or both.

The intake of diets containing SP has been previously reported to affect lipid metabolism, hepatic gene expression and antioxidant activity (Schwerin et al., 2002; Lin et al., 2005; Tachibana et al., 2005). In our study, apolipoprotein A-1 and apolipoprotein C-III, 2 proteins related to lipid transport between tissues, were also expressed at a lower level in the SPAA group in all 3 tissues investigated as compared with the control. The biological meaning of this observation is not clear because no data on overall lipid metabolism in these animals are available.

Concomitant with a downregulation of proteins associated with lipid metabolism, we found an upregulation of enzymes involved in glycolysis (triosephosphate-isomerase, alpha-enolase) and fructose and mannose me- 

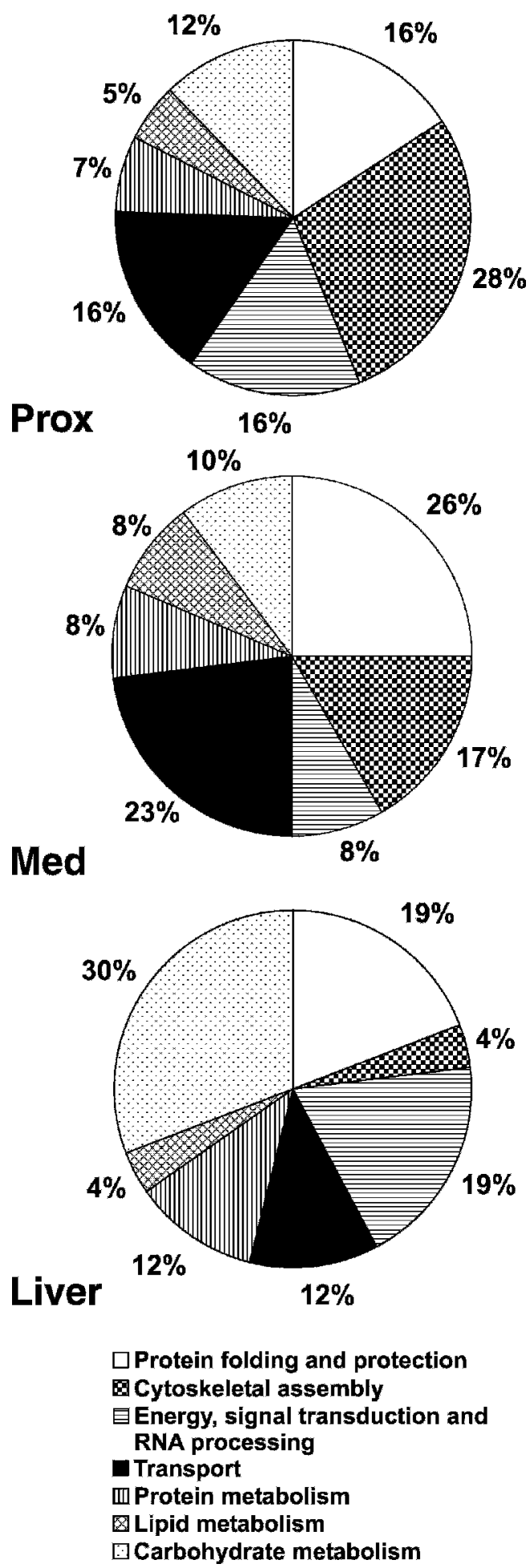

Figure 5. Relative proportion of total numbers of proteins identified in proximal (prox), medial (med) jejunal mucosa and liver samples of goat kids fed MP or SPAA belonging to 7 selected functional groups. Reading example: prox, $28 \%$ of identified proteins are molecules belonging to cytoskeletal proteins. $\mathrm{MP}=$ milk diet containing $\mathrm{CN}(35 \%$ of the milk CP was replaced by casein). SPAA = milk diet containing soy protein product supplemented with AA (35\% of total CP in the diet). tabolism (sorbitol dehydrogenase, aldo-keto reductase family 1) mainly in jejunum but a simultaneously lower expression of hepatic alpha-enolase, catalyzing the ninth step of glycolysis, and mitochondrial malate dehydrogenase, catalyzing the conversion of malate to oxaloacetate in the citric acid cycle. Available data on the effects of SP on carbohydrate or glucose metabolism are few. In rats no difference in blood glucose was found between animals fed a SP or casein-based diet, whereas in pigs SP isolate feeding increased hepatic glycogen content (Junghans et al., 2004a; Tachibana et al., 2005). Whether one of these findings is relevant for the observed changes in protein abundance due to SPAA is presently unclear.

Glutathione S-transferase P (EC 2.5.1.18), a molecule involved in the detoxification of oxygen radicals and xenobiotics was upregulated in the jejunum of the SPAA group, but no diet-related difference was seen in the liver. Previous studies with pigs and rats fed SP isolate demonstrated an upregulation of hepatic glutathione S-transferase mRNA and other antioxidant molecules (Schwerin et al., 2002; Tachibana et al., 2005) but on the proteome level appeared exclusively in the SP group (Junghans et al., 2004b).

In summary, we found in goat kids fed the SPAA diet a downregulation of the 3 proteins tropomyosin 1 alpha chain, tropomyosin alpha 4 chain, and PDZ and LIM domain protein 1 related to the cytoskeleton and muscle contraction, which is associated to alterations of jejunal morphology. Proteasome subunit alpha type 2 and proteasome subunit alpha type 4 belonging to the major cellular proteolytic system were upregulated, whereas 40 S ribosomal protein S12 involved in the protein synthesis machinery and the proteins histidine triad nucleotide-binding protein 1, rho GDP-dissociation inhibitor 2 , and brain creatine kinase related to energy and signal transduction were concurrently downregulated.

In conclusion, it appears that differences in the jejunal and hepatic proteome due to the SPAA diet are not as distinct as demonstrated in other studies with severe single nutrient deficiencies (tom Dieck et al., 2005; Tosco et al., 2005), which is in line with no apparent impact on animal growth and possibly due to the comparatively small difference between the 2 diets fed in the present study.

\section{REFERENCES}

Bradford, M. M. 1976. A rapid and sensitive method for the quantitation of microgram quantities of protein utilizing the principle of protein-dye binding. Anal. Biochem. 2:248-254.

Chanson, A., T. Sayd, E. Rock, C. Chambon, V. Sante-Lhoutellier, G. P. de Courcy, and P. Brachet. 2005. Proteomic analysis reveals changes in the liver protein pattern of rats exposed to dietary folate deficiency. J. Nutr. 135:2524-2529. 
Chen, A. C., M. A. Berhow, K. A. Tappenden, and S. M. Donovan. 2005. Genistein inhibits intestinal cell proliferation in piglets. Pediatr. Res. 57:192-200.

Corzo, A., M. T. Kidd, W. A. Dozier, III, L. A. Shack, and S. C. Burgess. 2006. Protein expression of pectoralis major muscle in chickens in response to dietary methionine status. Br. J. Nutr. 95:703-708.

Corzo, A., M. T. Kidd, M. D. Koter, and S. C. Burgess. 2005. Assessment of dietary amino acid scarcity on growth and blood plasma proteome status of broiler chickens. Poult. Sci. 84:419-425.

Coux, O., K. Tanaka, and A. L. Goldberg. 1996. Structure and functions of the 20S and 26S proteasomes. Annu. Rev. Biochem. 65:801-847.

D’Ambrosio, C., S. Arena, F. Talamo, L. Ledda, G. Tenzone, L. Ferrara, and A. Scaloni. 2005. Comparative proteomic analysis of mammalian animal tissues and body fluids: Bovine proteome database. J. Chromatogr. B. 815:157-168.

Daniel, H. 2002. Genomics and proteomics: Importance for the future of nutrition research. Br. J. Nutr. 87:305-311.

Deutz, N. E. P., M. J. Bruins, and P. B. Soeters. 1998. Infusion of soy and casein protein meals affects interorgan amino acid metabolism and urea kinetics differently in pigs. J. Nutr. 128:2435-2445.

Drackley, J. K., P. M. Blome, K. S. Bartlett, and K. L. Bailey. 2006. Supplementation of $1 \% \mathrm{~L}$-Glutamine to milk replacer does not overcome the growth depression in calves caused by soy protein concentrate. J. Dairy Sci. 89:1688-1693.

Ellederova, Z., P. Halada, P. Man, M. Kubelka, J. Motlik, and H. Kovarova. 2004. Protein patterns of pig oocytes during in vitro maturation. Biol. Reprod. 71:1533-1539.

Fuchs, D., B. Dirscherl, J. H. Schroot, H. Daniel, and U. Wenzel. 2006. Soy extract has different effects compared with the isolated isoflafones on the proteome of homocysteine-stressed endothelial cells. Mol. Nutr. Food Res. 50:58-69.

Fuchs, D., P. Erhard, G. Rimbach, H. Daniel, and U. Wenzel. 2005. Genistein blocks homocysteine-induced alterations in the proteome of human endothelial cells. Proteomics 5:2808-2818.

Gianazza, E., D. Veber, I. Eberini, F. R. Buccellato, E. Mutti, L. Sironi, and G. Scalabrino. 2003. Cobalamin (vitamin B12)-deficiencyinduced changes in the proteome of rat cerebrospinal fluid. Biochem. J. 374:239-246.

Görg, A., C. Obermaier, G. Boguth, A. Harder, B. Scheibe, R. Wildgruber, and W. Weiss. 2000. The current stand of two-dimensional electrophoresis with immobilized $\mathrm{pH}$ gradients. Electrophoresis 21:1037-1053

Jentsch, W., A. Chudy, and M. Beyer. 2003. M. Rostock Feed Evaluation System. Plexus Verlag, Miltenberg-Frankfurt, Germany.

Junghans, P., M. Derno, W. Jentsch, S. Kuhla, and M. Beyer. 2004a. Effect of a soy protein diet on protein and energy metabolism and organ development in protein-restricted growing pigs. Arch. Anim. Nutr. 58:453-461.

Junghans, P., T. Kaehne, M. Beyer, C. C. Metges, and M. Schwerin. 2004b. Dietary protein-related changes in hepatic transcription correspond to modifications in hepatic protein expression in growing pigs. J. Nutr. 134:43-47.

Kanjanapruthipong, J. 1998. Supplementation of milk replacers containing soy protein with threonine, methionine, and lysine in the diets of calves. J. Dairy Sci. 81:2912-2915.

Laemmli, U. K. 1970. Cleavage of structural proteins during the assembly of the head of bacteriophage T4. Nature 227:680-685.

Lallès, J. P. 1993. Nutritional and anti-nutritional aspects of soybean and field pea proteins used in veal calf production: A review. Livest. Prod. Sci. 34:181-202.
Lin, C. Y., C. Y. Tsai, and S. H. Lin. 2005. Effects of soy components on blood and liver lipids in rats fed high-cholesterol diets. World J. Gastroenterol. 11:5549-5552.

Luhn, S., M. Berth, M. Hecker, and J. Bernhardt. 2003. Using standard positions and image fusion to create proteome maps from collections of two-dimensional gel electrophoresis images. Proteomics 3:1117-1127.

Metges, C. C., A. E. El-Khoury, A. B. Selvaraj, R. H. Tsay, A. Atkinson, M. M. Regan, B. J. Bequette, and V. R. Young. 2000. Kinetics of $\mathrm{L}-(1-13 \mathrm{C})$ leucine when ingested with free amino acids, unlabeled or intrinsically labeled casein. Am. J. Physiol. Endocrinol. Metab. 278:E1000-E1009.

NRC. 1998. Nutrient Requirement of Swine. 10th rev. ed. Natl. Acad. Press, Washington, DC.

Payne, R. L., T. D. Bidner, L. L. Southern, and J. P. Geaghan. 2001. Effects of dietary soy isoflavones on growth, carcass traits, and meat quality in growing-finishing pigs. J. Anim. Sci. 79:12301239.

Pelaez, R., and D. M. Walker. 1979. Milk replacer for preruminant lambs: Limiting amino acids in two soybean protein isolates determined with a change-over design. Aust. J. Agric. Res. 30:125-134.

Ren, M. Q., G. Kuhn, J. Wegner, and J. Chen. 2001. Isoflavones, substances with multi-biological and clinical properties. Eur. J. Nutr. 40:135-146.

Schoenhusen, U., S. Kuhla, R. Zitnan, K. D. Wutzke, K. Huber, S. Moors, and J. Voigt. 2007. Effect of a soy protein based diet on the ribonucleic acid metabolism in the small intestinal mucosa of goat kids. J. Dairy Sci. 90:2404-2412.

Schwerin, M., U. Dorroch, M. Beyer, H. Swalve, C. C. Metges, and P. Junghans. 2002. Dietary protein modifies hepatic gene expression associated with oxidative stress responsiveness in growing pigs. FASEB J. 16:1322-1324.

Seegraber, F. J., and J. L. Morrill. 1986. Effect of protein source in calf milk replacers on morphology and absorptive ability of small intestine. J. Dairy Sci. 69:460-468.

Society of Nutrition Physiology. 2001. Ausschuss für Bedarfsnormen der Gesellschaft für Ernährungsphysiologie. No. 8. Empfehlungen zur Energie- und Nährstoffversorgung der Milchkühe und Aufzuchtrinder (Recommended energy and nutrient supply for dairy cows and growing cattle). DLG-Verlag, Frankfurt, Germany.

Tachibana, N., I. Matsumoto, K. Fukui, S. Arai, H. Kato, K. Abe, and $\mathrm{K}$. Takamatsu. 2005. Intake of soy protein isolate alters hepatic gene expression in rats. J. Agric. Food Chem. 53:4253-4257.

tom Dieck, H., F. Döring, D. Fuchs, H. P. Roth, and H. Daniel. 2005. Transcriptome and proteome analysis identifies the pathways that increase hepatic lipid accumulation in zinc-deficient rats. J. Nutr. 135:199-205.

Tosco, A., R. A. Siciliano, G. Cacace, M. F. Mazzeo, R. Capone, A. Malorni, A. Leone, and L. Marzullo. 2005. Dietary effects of copper and iron deficiency on rat intestine: A differential display proteome analysis. J. Proteome Res. 4:1781-1788.

Wang, J., D. Li, L. J. Dangott, and G. Wu. 2006. Proteomics and its role in nutrition research. J. Nutr. 136:1759-1762

Zitnan, R., S. Kuhla, U. Schönhusen, J. Voigt, M. Levkut, V. Revajova, I. Tomkova, M. Brna, M. Zupacanova, and M. Hudakova. 2005. Effects of soya protein intake upon the development of the intestinal tract of suckling kids. Agriculture (Pol'nohospodarstvo) $51: 30-35$.

Zitnan, R., J. Voigt, U. Schönhusen, J. Wegner, M. Kokardova, H. Hagemeister, M. Levkut, S. Kuhla, and A. Sommer. 1998. Influence of dietary concentrate to forage ratio on the development of rumen mucosa in calves. Arch. Anim. Nutr. 51:279-291. 